couver Island Health Authority in Victoria, British Columbia.

"Studies have shown that a short, simple message does have an effect," says Watters. "That simple message has an impact on patient behaviour. It's important that physicians are aware of this impact."

Watters teaches nutrition courses to medical students, and says they often tell her that nutrition should be taught earlier in their programs and integrated throughout the curriculum. That would be more likely to happen, she says, if medical faculties had more staff quali- fied to teach nutrition. "We have anatomy professors," she says. "We need nutrition professors."

Some medical schools appear to be moving in that direction. For instance, The University of Ottawa Faculty of Medicine in Ottawa, Ontario, recently appointed a staff member to be the leader on nutrition. The school will now be dedicating a week to obesity education and is in the process of revising its curriculum to include more instruction on nutrition, which staff included in a list of 18 "hot topics" that required greater attention.

"Society tends to focus on different aspects of health at different times and, in general, nutrition has historically not been high up on the list of important topics," says Dr. Geneviève Moineau, associate dean of undergraduate medical education at the University of Ottawa. "I think we now realize that there are so many health issues that directly relate to nutrition, whether we are talking about obesity, eating disorders or other diseases that we now know we can prevent by proper nutrition." - Roger Collier, CMAJ

DOI:10.1503/cmaj.091163

\title{
Shortages no more: Fixing the isotope supply chain
}

$\mathrm{W}$

hen something as important as the world's medical isotope supply can be compromised by the closure of a single facility, people get worried. With another isotope shortage causing them grief, nuclear medicine practitioners appear worried enough to look beyond short-term workarounds to long-term solutions.

Some nuclear experts are exploring how the world became so dependent on so few reactors. This problem has been of great concern since May, when the reactor in Chalk River, Ontario, went off-line due to a heavy-water leak.

"How did we get ourselves into this corner?" says Jatin Nathwani, Ontario research chair in public policy for sustainable energy management. "If you reflect upon it, this reliance on old and aging reactors as the critical suppliers of medical isotopes, you just shake your head."

Nathwani, a professor of management sciences at the University of Waterloo, has twice appeared before the House of Commons Committee on Natural Resources to discuss this problem. He is not encouraged, however, by the government's announcement that it will stop producing isotopes after the Chalk River reactor shuts down permanently, likely in 2016. Nathwani says this will only create more problems for Canada, making it wholly dependant on other countries. "That is not a credible long-term view."

Dr. Andrew Einstein, an assistant professor of clinical medicine at Colum-

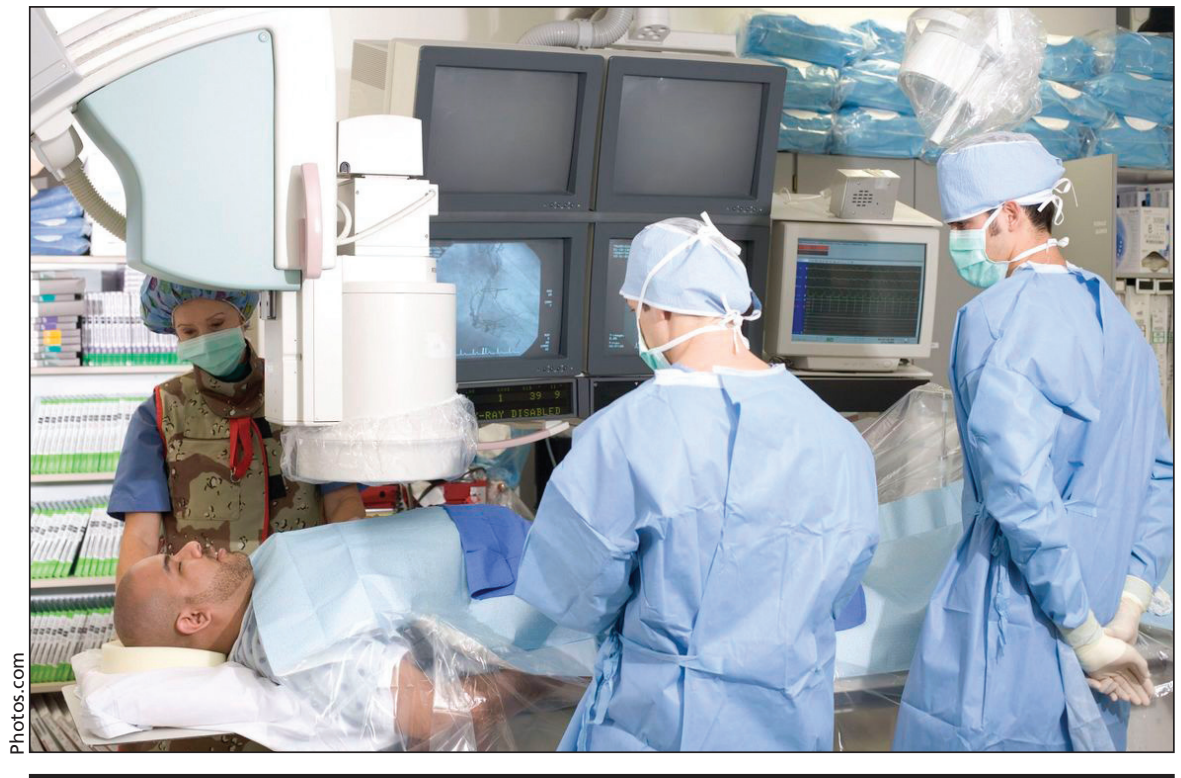

Nuclear medicine practitioners are tired of rescheduling diagnostic procedures because of isotope shortages. They are looking for ways to secure the global isotope supply.

bia University in New York, says some people have suspected the overdependence on a few reactors would lead to trouble. "If you look back in the literature over the past 20 years, you see periodic statements about the tenuousness of the supply," he says. "But as long as the supply was coming, no one challenged the status quo."

Now, however, maintaining the status quo isn't an option, says Einstein. "There is just not enough reserve in the system. There is a need for more reactors so that we are not so dependent on the perfect functioning of the reactors we have."

Some nuclear experts say the problem is not a lack of reactors, but a lack of coordination between parties capable of producing raw isotopes (those with facilities where uranium targets can be irradiated with neutrons) and those capable of processing them into a form for use in nuclear medicine (molybdenum-99). "There are lots and lots of reactors around the world that are underutilized, yearning for someone to buy their neutrons," says Alan Kuperman, director of the Nuclear Proliferation Prevention 
program. "And then you have folks who have targets that just want neutrons. There is just a market failure in bringing the targets to the reactors that exist."

Besides, building new reactors is something few parties seem willing to do. The start-up costs are immense. It takes years to meet regulatory standards, start production and establish a distribution network. And existing isotope producers, who have long enjoyed a marketplace with few competitors, might not play nice.

"There are always, when you have a cartel, going to be competitive tactics used to prevent new entrants," says Kuperman, a professor of public affairs at the University of Texas at Austin. "Existing producers divide up the market. If anyone else tries to come in, the existing producers will undercut them, even taking a loss in the short run."

Further discouraging potential entrants to the market was the fact that 2 new Canadian reactors, designed specifically to produce isotopes, were expected to begin production in 2000 . But these reactors, known as the MAPLE (Multipurpose Applied Physics Lattice Experiment) reactors, suffered technical difficulties, and the Canadian government scrapped the project in May 2008.

Reviving the project, some say, might be the best solution to securing the world's isotope supply. MDS Nordion, the Canadian isotope producer that invested \$350 million in the project, has suggested that the government bring in a committee of international experts to take another look at the reactors.

"With the MAPLEs in the mix, with all existing reactors, you have a very stable supply of medical isotopes," says Jill Chitra, vice-president of strategic technologies for MDS Nordion.

Some nuclear experts, such as Kuperman, say that much effort and money has already been put into solving the MAPLE reactors' safety problems, and there is no reason to believe another look will produce favourable results. But others, including Nathwani, say that since the reactors are already capable of producing isotopes despite their technical issues, it makes sense for the government to reconsider its decision to cancel the project.
Other proposed fixes for the world's wonky isotope supply chain include increasing production at research reactors (such as the ones located at McMaster University in Hamilton, Ontario, and the University of Missouri in Columbia) and building cheaper reactors. In January, The Babcock \& Wilcox Company, based in Virginia, signed an agreement with the global health care company Covidien to produce isotopes in solutionbased reactors, which the companies claim will be less complex, less expensive and more environmentally friendly than traditional reactors.

Whether the reactors are new or refurbished is less important than avoiding reliance on just one, says Cyrille Villeneuve, vice-president and general manager of the international division of Lantheus Medical Imaging, which has headquarters in North Billerica, Massachusetts, with offices in Puerto Rico, Canada and Australia. As part of its "supply chain diversification strategy," the company, which plans to soon ship isotopes to North America, recently signed agreements to receive raw isotopes from South Africa and from a reactor owned by the Australian Nuclear Science and Technology Organisation.

"This is the way to go for the future," says Villeneuve. "We need to have diversity of supply. We need to buy from all suppliers at a certain level. It is now a consensus in the industry that buying from one supplier is not good."

Another possible way to put an end to isotope shortages is to develop new diagnostic technologies that don't need isotopes or require lower doses. The Canadian government recently promised \$6 million to scientists to find such alternatives. In the meantime, it is important that communication between isotope suppliers and consumers be improved, says Dr. Sandy McEwan, who was recently appointed as a special adviser to Health Minister Leona Aglukkaq. "One of the big issues that face people is the uncertainly of their supply. If they can be warned that there will be a shortage of supply in 2 or 3 weeks, they could adjust their workload accordingly." - Roger Collier, CMAJ

DOI:10.1503/cmaj.091255 